\title{
Delineating ethnic and religious identities in research with British South Asians
}

\author{
Rusi Jaspal \\ Royal Holloway, University of London
}

The present essay presents a rationale for delineating ethnic and religious identities in empirical research into self-identification among British South Asians. It is argued that the delineation of these identities is important in order to (i) predict and explain the identificatory possibilities available to these individuals; (ii) explore the differential values attributed to these identities; (iii) the level of psychological 'connectedness' between the identities; and (iv) the inter-relations between these identities, particularly in relation to psychological coherence. It is argued that a systematic delineation of these identities may have favourable theoretical, empirical and practical outcomes.

Keywords: British South Asians; ethnic identity; religious identity; research; social psychology

Citing this article: Jaspal, R. (in press). Delineating ethnic and religious identities in research with British South Asians. Psychological Studies.

Address for correspondence: Rusi Jaspal, Department of Psychology, Royal Holloway, University of London, Egham Hill, Egham, Surrey TW20-OEX, United Kingdom, Tel: +44 (0)1784-276323, Fax: +44 (0)1784 434347, E-mail: rusi.jaspal@ gmail.com 


\title{
Delineating ethnic and religious identities in research with British South Asians
}

\author{
Rusi Jaspal \\ Royal Holloway, University of London
}

\begin{abstract}
The present essay presents a rationale for delineating ethnic and religious identities in empirical research into self-identification among British South Asians. It is argued that the delineation of these identities is important in order to (i) predict and explain the identificatory possibilities available to these individuals; (ii) explore the differential values attributed to these identities; (iii) the level of psychological 'connectedness' between the identities; and (iv) the inter-relations between these identities, particularly in relation to psychological coherence. It is argued that a systematic delineation of these identities may have favourable theoretical, empirical and practical outcomes.
\end{abstract}

Keywords: British South Asians; ethnic identity; religious identity; research; social psychology

Ethnic identity is one dimension of the self, which has received significant empirical and theoretical attention in social psychology (Hofman, 1988; Phinney et al., 2001; Taylor \& Brown, 1988; Verkuyten, 2005). Within the British context, social psychologists, sociologists and anthropologists have exhibited interest in ethnic identity construction among the largest ethnic minority group in Britain, namely British South Asians (Ghuman, 2003; Modood et al., 1997; Hutnick \& Street, 2010; Jaspal \& Cinnirella, 2010b; Robinson, 2009). This superordinate umbrella category is most frequently employed to denote first, second and third generation Britons with Indian, Pakistani or Bangladeshi origins. The growing theoretical and empirical interest in British South Asian ethnic identity means that researchers should be sensitised to some of the theoretical and methodological challenges associated with conducting research in this field. One such challenge concerns the delineation of ethnic and religious identities, which are often conflated by researchers. This short essay provides some commentary regarding the importance of delineating ethnic and religious identities among British South Asians. In particular, it will be demonstrated how a delineation of these identities enables the researcher to explain and predict patterns of social identification, the evaluation and 'connectedness' of ethnic and religious identities, and interactions between them.

In order to explain and predict the identificatory possibilities available to individuals, researchers must logically attempt to discern the various dimensions of self which are of phenomenological importance to social actors themselves. Among British South Asians, one particularly important dimension is religious identity, which, partly due to the loose conceptual criteria of ethnicity, is often subsumed under the more general category of ethnicity (Jacobson, 1997). Although religious identity may form part of one's ethnic identity, recent works highlight the importance of religious identity vis-à-vis other identities (Jacobson, 1997; Kibria, 2008; Raj, 2000). Jaspal and Coyle (2010, p. 19) have remarked that 'religious identity might refer to a system of religious beliefs for some, whereas for others it could be akin to a form of cultural identity'. Advocates of greater conceptual delineation of religious and ethnic identities are acutely aware of the significance of religious belief in the construction of religious identity among Muslims, for instance (Jacobson, 1997; Jaspal \& Cinnirella, 2010a). For instance, many 
Muslims would construe Muslim converts as members of their religious ingroup but not necessarily as members of their ethnic ingroup. This suggests that the two social identities, though inter-related, are likely to be qualitatively different and, thus, delineable. As Deaux (1993, p. 8) observes, 'knowing which identities a person claims is not enough', but rather ascertaining the position of the identity within the broader identity structure and particularly in relation to other identities is likely to predict the individual's affective state and choice of behaviour. Thus, it seems necessary to conceptualise and operationalise ethnic and religious identities as separate identity components in quantitative research into the self among British South Asians in order to explore the inter-relations between these components. Moreover, by recognising religious and ethnic identification as two potentially distinct modes of selfidentification, researchers will be in a better position to explain and predict these identificatory patterns.

It is noteworthy that some scholars continue to regard these identities as highly interrelated. Anwar (1998) has stated that, for a majority of British South Asians, religion underlies ethnic identity construction. This suggests that religion is a component of ethnic identity rather than a discrete identity in itself. This may be particularly applicable to British Pakistanis, who generally regard Pakistani ethnic and Muslim religious identity as inextricably related (Dwyer, 1999). However, in a recent quantitative survey study on self-identification among British Indians, participants scored a mean of 3.87 on an 8-point scale measuring the degree of 'connectedness' between ethnic and religious identities, suggesting that these identities are not particularly connected in the minds of British Indians (Jaspal, 2011). On the other hand, there are now a number of empirical studies, which demonstrate that among British Pakistanis it is in fact religious, and not ethnic, identity which takes precedence over all other social identities (Jacobson, 1997; Modood et al., 1997; Rosowsky, 2008). In fact, these studies have demonstrated how the two identities may in fact be in conflict with one another. For instance, Jaspal and colleagues (Jaspal \& Cinnirella, 2010a; Jaspal \& Coyle, 2010) have found that in order to highlight the importance of their religious identities, British Muslim participants may actively denigrate their ethnic identities. This is consonant with theorising on psychological coherence, which refers to the individual's need to perceive their inter-connected identities as compatible and coherent (Jaspal \& Cinnirella, 2010a). It is stated that, in order to safeguard coherence, the identities in question will be attributed positive and negative values, which enables the individual to position them coherently within the identity structure. For instance, in a study on British Muslim gay men, some participants positively evaluated their religious identity and negatively evaluated their sexual identity in order to enhance coherence (Jaspal \& Cinnirella, 2010a). This demonstrates the importance of delineating ethnic and religious identities, since it is possible that the evaluation process of identity will function differently in relation to either identity (Breakwell, 1986). This may in turn shed light upon issues surrounding multiple identification, which are of growing importance in multicultural Britain. This may inform academic and public debate regarding the management of British national, ethnic and religious identities among British South Asians.

Qualitative research into British South Asian identity tends to demonstrate a clear differentiation between the two identities in participants' psychological worlds. Jacobson (1997), for instance, finds that revivalist Islam may provide young Pakistanis with the psychological tools to justify their rejection of their parents' cultural norms and values. Revivalist Muslims may view these norms and values as being 'distorted' aspects of their ethnic culture and thus distant from Islamic teachings. Thus, one identity within the self-concept 
(Islam) is invoked in order to justify the rejection of other self-aspects associated with their ethnic identity (e.g. ethno-cultural values, norms and practices). Indeed, Breakwell (1986) predicts in identity process theory that individuals will strategically make use of their multiple group memberships in order to cope with identity threat (e.g. perceived threats to continuity of Islamic identity, as suggested by perceiving ethnic elements to be 'distorted'). Crucially, if individuals perceive a self-aspect from one social identity to jeopardise their sense of continuity, for instance, they may provide 'counter-examples' or retaliatory responses by invoking aspects of other social identities. Kibria (2008) notes that revivalist Islam can offer British and American Bangladeshi youth a powerful means to assert a positive and distinctive sense of identity in spite of the marginalisation that they face in their respective dominant societal contexts. From the perspective of identity process theory, this exemplifies the resourcefulness of individuals since both the distinctiveness and belonging principles of identity are actively enhanced through self-identification with religion vis-à-vis disidentification from ethnicity. Here too it appears that religious identity takes precedence over other identities. Crucially, these important hypotheses regarding self-identification, identity processes and identity threat can be satisfactorily explored through a systematic delineation of ethnic and religious identities.

The consequences of losing sight of the inter-relations between these potentially conflictual identities may be negative. For instance, Jaspal \& Coyle $(2009,2010)$ argue that British South Asian youths may experience dilemmas, feelings of confusion and even shame in their attempts to reconcile their religious and ethnic identities. When religious contexts were invoked, Muslim participants exhibited the tendency to positively evaluate their liturgical languages Arabic and Urdu, which were seen as being closely related to religious identity. Conversely, in other (non-religious) contexts they constructed their ethnic languages (e.g. Mirpuri, Punjabi) as superior. The dilemmatic thinking of several participants was observable in their frequently contradictory attitudes regarding the languages per se; a language was either viewed as 'good' or 'bad'. This could be attributed to the varying social representations associated with both religious and ethnic identities, which dictate which is to be considered the 'appropriate' language for communication (Moscovici, 1988). By delineating ethnic and religious identities, the researcher may is better equipped, theoretically and empirically, to explore the differential social representations associated with each social identity.

These social representations will inform individuals' personal perceptions of their identities. It has been demonstrated that specific languages (or individuals' ethnolinguistic identities) may be viewed by other group members as being incompatible with particular social identities (Jaspal \& Coyle, 2010). This was said to be conducive to feelings of exclusion by speakers with 'incompatible' ethnolinguistic identities, resulting in threats to belonging. Perceived exclusion possibly led some participants to develop and to activate strategies to minimise the ensuing identity threat by rejecting social representations indicating a close relationship between ethnic/ religious identity and specific languages. The central point here is that only the systematic differentiation between ethnic and religious identities enables the researcher to engage with issues of identity threat and the coping strategies which may subsequently be activated. These are crucial issues with consequences for psychological wellbeing (Jaspal \& Cinnirella, 2010a). Moreover, these issues are particularly pertinent to British South Asians many of whom find themselves in the intricate position of having to 'manage' their multiple ethnic, religious and national identities (Ghuman, 2003, 2005; Jaspal \& Cinnirella, 2010b). 


\section{Concluding thoughts}

It is acknowledged that identification with common religious beliefs, norms and values may bind a social group and contribute to social representations of common origin and heritage, which in turn encourages ethnic identity formation (Smith, 1986). This is most likely applicable to those individuals who express their religious identity in cultural terms, rather than those who regard their religious identity in terms of a belief system. However, there is some empirical evidence that British Indians do not regard their religious and ethnic identities to be highly 'connected'. Moreover, it has been argued that only an empirical delineation of ethnic and religious identities will allow insight into how these identities may be differentially evaluated by individuals, both separately and within the context of one another. This may be important in elucidating how individuals manage the co-existence of these identities within the self-concept. A consideration of the management of these identities may allow researchers to explain how and predict when self-aspects from one social identity will be accepted or rejected by the individual. This feeds back productively into research regarding intergenerational relations (Ghuman, 2005). Crucially, it is likely that these questions have important implications for psychological well-being among British South Asians, who are habitually engaged in the management of their multiple identities. Questions surrounding multiple identification among British South Asians are of growing importance, particularly after the July $7^{\text {th }}$ bombings in London, which were perpetrated mainly by British citizens of South Asian descent. These unprecedented events raised questions regarding the compatibility of national, ethnic and religious identities among ethnic minority youth. Academic studies and practical interventions which appreciate the phenomenological differences between ethnic and religious identities among British South Asians will likely enhance our understanding of identity management in this population. It is hoped that this commentary will encourage researchers in this area to appreciate the potential phenomenological differences associated with ethnic and religious identification among British South Asians.

\section{References}

Anwar, M. (1998). Between Cultures: Continuity and Change in the Lives of Young Asians. London: Routledge.

Breakwell, G.M. (1986) Coping with threatened identities. London: Methuen.

Deaux, K. (1993). Reconstructing social identity. Personality and Social Psychology Bulletin, 19(1), 4-12.

Dwyer, C. (1999). Contradictions of community: questions of identity for young British Muslim women. Environment and Planning A, 31, 53-68.

Ghuman, P.A.S. (2003). Double Loyalties: South Asian Adolescents in the West. Cardiff: University of Wales Press.

Ghuman, P.A.S. (2005). Daughters of tradition. The Psychologist, 18(10), 620-22.

Hofman, J.E. (1988). Social identity and intergroup conflict: an Israeli view. In W. Stroebe, A.W. Kruglanski, D. Bar-Tal and M. Hewstone (Eds.), The Social Psychology of Intergroup Conflict. New York: Springer Verlag.

Hutnik, N. \& Street, R.C. (2010) Profiles of British Muslim Identity: Adolescent Girls in Birmingham. Journal of Adolescence, 33, 33-42.

Jacobson, J. (1997). Religion and ethnicity: Dual and alternative sources of identity among young British Pakistanis. Ethnic and Racial Studies, 20(2), 238-256.

Jaspal, R. (2011). The construction and management of national and ethnic identities among British South Asians: an identity process theory approach. Unpublished $\mathrm{PhD}$ dissertation, 
Royal Holloway, University of London, UK.

Jaspal, R. \& Cinnirella, M. (2010a). Coping with potentially incompatible identities: accounts of religious, ethnic and sexual identities from British Pakistani men who identify as Muslim and gay. British Journal of Social Psychology, 49, 849-870

Jaspal, R. \& Cinnirella, R. (2010b). The construction of ethnic identity: insights from identity process theory. Manuscript submitted for publication.

Jaspal, R. \& Coyle, A. (2009). Language and perceptions of identity threat. Psychology and Society, 2(2), 150-167.

Jaspal, R. \& Coyle, A. (2010). 'Arabic is the language of the Muslims - that's how it was supposed to be': exploring language and religious identity through reflective accounts from young British-born South Asians. Mental Health, Religion and Culture, 13(1), 17-36

Kibria, N. (2008). The new Islam and Bangladeshi youth in Britain and the U.S. Ethnic and Racial Studies, 31(2), 243-266.

Modood, T., Berthoud, R., Lakey, J., Nazroo, J., Smith, P., Virdee, S. \& Beishon, S. (1997). Ethnic Minorities in Britain: Diversity and Disadvantage. London: Policy Studies Institute.

Moscovici, S. (1988). Notes towards a description of social representations. European Journal of Social Psychology, 18, 211-250.

Phinney, J.S., Horenczyk, G., Liebkind, K. \& Vedder, P. (2001). Ethnic identity, immigration and well-being: An interactional perspective. Journal of Social Issues, 57(3), 493510 .

Raj. S.D. (2000). "Who the hell do you think you are?'” Promoting religious identity among Young Hindus in Britain. Ethnic and Racial Studies, 23(3), 535-58.

Robinson, L. (2009). Cultural identity and acculturation preferences among South Asian adolescents in Britain: An exploratory study. Children and Society, 23(6), 442-454.

Rosowsky, A. (2008) Muslim, English, or Pakistani? Multilingual identities in minority ethnoreligious communities. In P. Martinez, D. Moore and V. Spaëth (Eds.), Plurilinguismes et Enseignement. Paris: Riveneuve.

Smith, A. D. (1986). The ethnic origins of nations. Oxford: Blackwell.

Taylor, S. E., \& Brown, J. D. (1988). Illusion and well-being: a socio-psychological perspective on mental health. Psychological Bulletin, 103, 193-210.

Verkuyten, M. (2005). The Social Psychology of Ethnic Identity. Hove: Psychology Press. 